\title{
Does Customer Experience Management Impact Customer Loyalty Shopping at Supermarket? The Case in the Mekong
} Delta, Vietnam

\author{
Luu Tien Thuan, Nguyen Huynh Bao Ngoc, Nguyen Thu Nha Trang \\ Can Tho University, Can Tho, Vietnam
}

\begin{abstract}
This research analyzes and answers the question "Does customer experience management impact to customer loyalty shopping at supermarket, in the case of Mekong Delta, Vietnam?”, 321 customers of supermarkets in the Mekong Delta were interviewed by questionnaire. The descriptive statistics, factor analysis, Cronbach's alpha, structural equation modeling, and multi-group structural analysis methods were used in this study. The results confirm that customer experience management impacts to customer loyalty shopping at supermarkets. There are six components of customer experience management including brand name, space, commodity, staff, parking lot, and the presence of other stores in supermarkets. In particular, the commodity composition has the strongest impact on customer experience management and satisfaction and directly influences on customer loyalty. In addition, elements of customer experience management affect customer loyalty indirectly through sensory experience, social experience, and satisfaction. The results of multivariate analysis show that age group, spending per shopping at supermarkets, and marital status of the client do not change the relationships in the research model. Meanwhile, the relationship of the different models of the client group income, gender, education, occupation and customers is different. This study adds value to consumer behavior and customer experience management literature.
\end{abstract}

Keywords: customer experience management, customer loyalty, satisfaction, supermarket

\section{Introduction}

Supermarket in the Mekong Delta Vietnam is changing rapidly and expressed as a retail market's potential. In 2010, the entire region had 17 supermarkets; however, until 2015 modern retail system was more competitive in 13 provinces and cities in the region with about 40 local and foreign supermarkets. To succeed and survive in the competition environment, supermarket managers need to design strategies to improve satisfaction and maintain customer loyalty better than competitors. Most companies recognize the benefits of customer loyalty. The previous study showed that the cost to entice a new customer typically was 9-10 times higher than the cost of retaining existing customers and decreased 5\% loss rate, increased 25-100\% profit (Reichheld, Markey, \& Hopton, 2000). Therefore, the construction of the loyalty of existing customers is

Luu Tien Thuan, Ph.D, Can Tho University, Can Tho, Vietnam.

Nguyen Huynh Bao Ngoc, M.Sc., Can Tho University, Can Tho, Vietnam.

Nguyen Thu Nha Trang, M.Sc., Can Tho University, Can Tho, Vietnam.

Correspondence concerning this article should be addressed to Luu Tien Thuan, College of Economics, Can Tho University, 3/2 Street, Can Tho city, Vietnam. 
essential to the supermarket in the Mekong Delta. However, to obtain a long-term commitment from the client side, supermarket managers need to identify factors affecting their customer loyalty. A new approach to building loyalty of customer is a customer experience management (CEM) approach. To create a positive experience, it is important to identify and understand the components of strategic CEM. Due to different cultural environment, consumers in each country may have different perceptions about the various components that make experience for them. Moreover, most of the researches on CEM and customer experience are carried out in developed countries. So in the case of developing country like Vietnam, does CEM impact on the loyalty of customers? The objectives of this study are to: (1) Identify the components of CEM in supermarkets; (2) Develop and test the relationship between CEM, customer experience, satisfaction, and loyalty; (3) Analyse of the differences in the relationships with different customer groups on consumer characteristics and personal characteristics; and (4) Propose a number of recommendations to improve customers experience and maintain customer loyalty to the supermarkets. This study is expected to contribute and enrich the literature on consumer behavior and CEM. The paper is structured into seven sections such as Introduction, Literature review, Research methods, Research results, Analysis and discussion, Conclusions, and References.

\section{Literature Review}

Customer satisfaction and loyalty: Customer satisfaction is the emotional response/feeling of customer with service providers' bases on comparing the difference between what they received and expected (Oliver, 1997). According to Sirdeshmukh, Singh, and Sabol (2002), the loyalty in the context of marketing is an intention to carry out a diverse set of behaviors signal, a motivation to maintain the relationship with the organization, including higher payment for a specific service provider, has a positive effect on the intention worth of mouth and repeated purchase. Loyalty is also defined as the commitment of customers, who would purchase products or services preferred (Chaudhuri, 1999), will give priority to buy products from a certain brand (Yoo, Donthu, \& Lee, 2000) in the future. In addition, acceptable buying at higher prices was mentioned by Shen and Zhao (2005) as an expression of loyalty to the client.

Customer experience management: With the aim of understanding, monitoring, supervision, and organization of all interactions between customer and business, the term CEM has been mentioned by many scholars. First, customer experience is defined as the sum of all experiences that a customer has a supplier/services provider. It can also be used as a personal experience rather than a transaction (Pine \& Gilmore, 1998). Smith and Wheeler (2002) have asserted that CEM is evaluating the valuable experience from the customer's satisfaction with their people, processes, and products/services. Schmitt (2003) emphasized that CEM is a process of strategically entire customer experience with a product or a company. According to Bernd Schmitt, the term CEM is also a set of techniques, methods, and processes used to manage a comprehensive channel exposure, interaction with business customers, and commercial product performance or service.

Vehoef, Lemon, and Parasuraman (2009) suggested that CEM is the factors that control the customer experience for developing a model and create experiences in the retail environment, in which the authors emphasized that the retailer can control the elements of the business such as social environment, services, atmosphere, characteristic of supermarkets, etc. to make the good experience and differentiate the customers. Moreover, Grewal, Levy, and Kumar (2009) mentioned that promotion, pricing, merchandise, and location are all factors which can create a great feeling to the customers. On the other hand, Kamaladevi (2010) reinforced the view of Vehoef et al. (2009) and pointed out that the customer experience is formed from a variety of channels 
retail environments such as brand, price, supported sales program, location, advertising, packaging and labeling services, and the atmosphere. The study also showed that the macro factors not only impact the customer experience, but also can affect the loyalty of consumers to the enterprise. Recently, Wijaithammarit and Taechamaneestit (2012) found a direct relationship between the components of management experience and loyalty. In particular, the components of customer experience management are a causal factor and the loyalty is the result factor. From the above statement, the hypothesis $\mathrm{H}_{1}, \mathrm{H}_{2}$, and $\mathrm{H}_{6}$ are as following:

$\mathrm{H}_{1}$ : The components of CEM have positive influence on sensory experience of customer.

$\mathrm{H}_{2}$ : The components of CEM have positive influence on social experience of customer.

$\mathrm{H}_{6}$ : The components of CEM have positive influence on the loyalty of customer.

To illustrate the effect of CEM components on customer experience, Kamaladevi (2010) pointed out that the more customer experience, the more customer satisfaction is. Besides, Ceribeli, Merlo, Senesi, and Palau (2012) provided evidence that customer satisfaction is dominated by experience in the procurement process. In turn, satisfaction is closely linked to loyalty. Rust and Zahorik (1993) found a link between satisfaction and loyalty in the case of banking and hotel industries. Fornell, Johnson, Anderson, Cha, and Everitt Bryant (1996) suggested that increasing satisfaction will enhance loyalty and repeat purchase rates. The hypotheses $\mathrm{H}_{3}, \mathrm{H}_{4}$, and $\mathrm{H}_{5}$ are set as following:

$\mathrm{H}_{3}$ : Social experience has positive influence on customer satisfaction.

$\mathrm{H}_{4}$ : Sensory experience has positive influence on customer satisfaction.

$\mathrm{H}_{5}$ : Customer satisfaction has positive influence on customer loyalty.

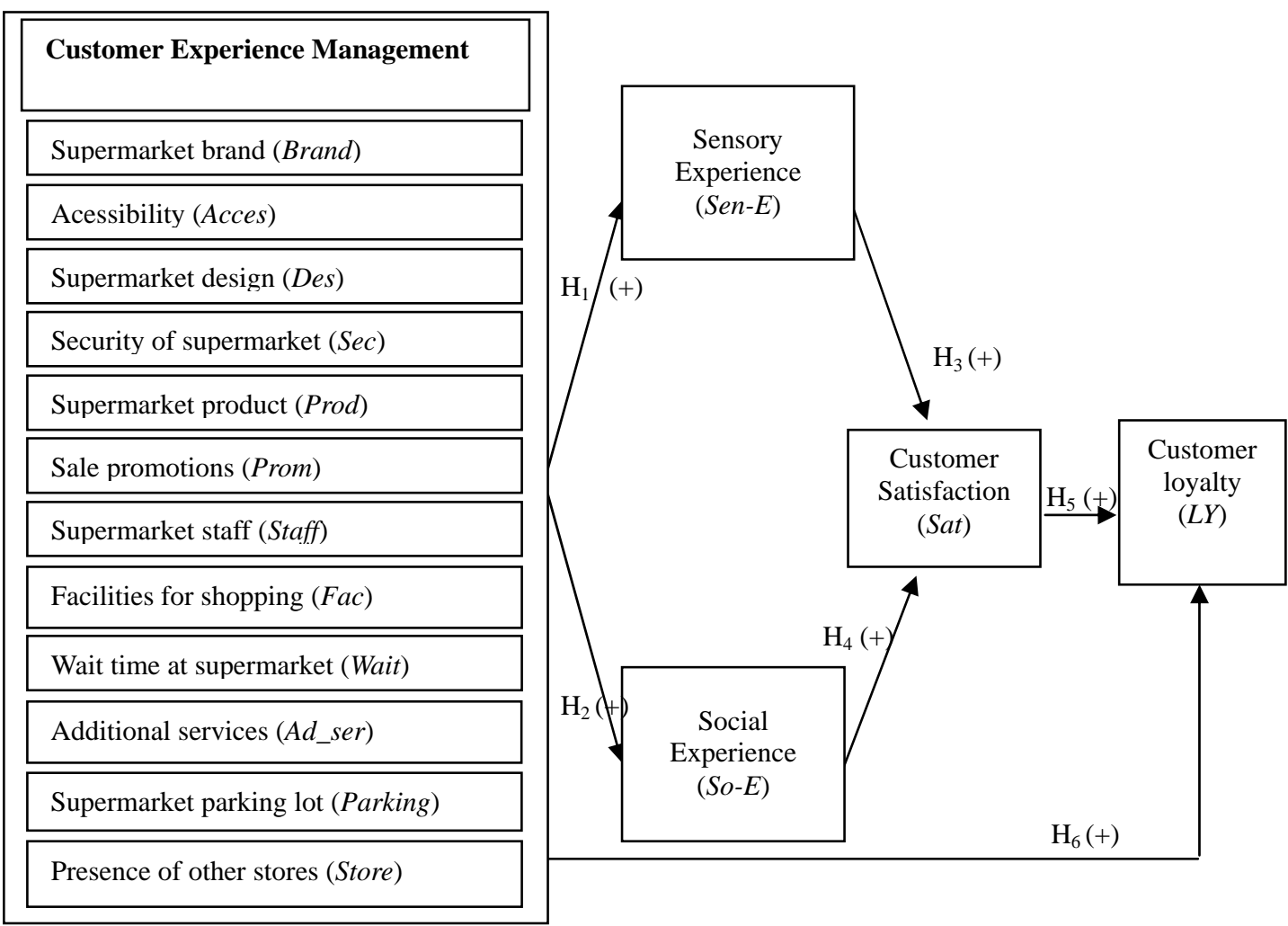

Figure 1. Research model. 


\section{Research Methods}

This study was carried out through two steps: explorative and quantitative research methods. Twenty respondents were interviewed and divided into group of four to six interviewees in the first step. The main purpose of this step is to clarify the discussion issues, edit and revise questionnaire. In the second step, 321 respondents who were shopping in the following supermarkets: Co.opmart, Metro, Big C, etc. were selected by convenience sampling method and conducted interview directly. These supermarkets are located in Can Tho, Bac Lieu, Long Xuyen, Rach Gia, Vinh Long, and Tra Vinh cities. All scales in this study are five-point Likert scale with 1: Strongly Disagree and 5: Strongly agree. Descriptive statistics, Cronbach's alpha, explorative factor analysis (EFA), confirmative factor analysis (CFA), and structural equation model (SEM) were used in this study.

\section{Research Results}

\section{Cronbach's Alpha Testing}

Cronbach's alpha was used to test the reliability of data. The results showed that eight observed variables were dropped out. On the other hand, Cronbach's alpha of components easy accessibility (Acces) variable is less than the permitted level $(0.554<0.6)$, so all the elements of this scale will be disqualified. After eliminating unsatisfactory variables, the components of CEM, sensory experience, social experience, satisfaction, and loyalty variables are satisfactory Cronbach's alpha reliability testing (from 0.687 to 0.819 ). The remaining 72 observed variables were used to performance next step of EFA.

\section{Explorative Factor Analysis (EFA)}

CEM variable: there are 33 observed variables which had loading factor coefficient of less than 0.5 should be removed from the model. The final EFA results found that there were six factors extracted within 21 observed variables, with $\mathrm{KMO}=0.797$, sig $=0.000$, the total variance extracted was $50.6 \%$. After factor analysis, 6 scale components of CEM without disruption observed variables between components, so called primary components remain the same. The four remaining variables in EFA process, the variables LY1, LY2, and LY3 of less than 0.5 should be released out the model. After analyzing EFA, the loading factor coefficient did not have the disturbance observed variables, the KMO coefficient, significant, and the total variance explained were extracted to be satisfactory, ready to conduct CFA.

Table 1

Summary of the Results

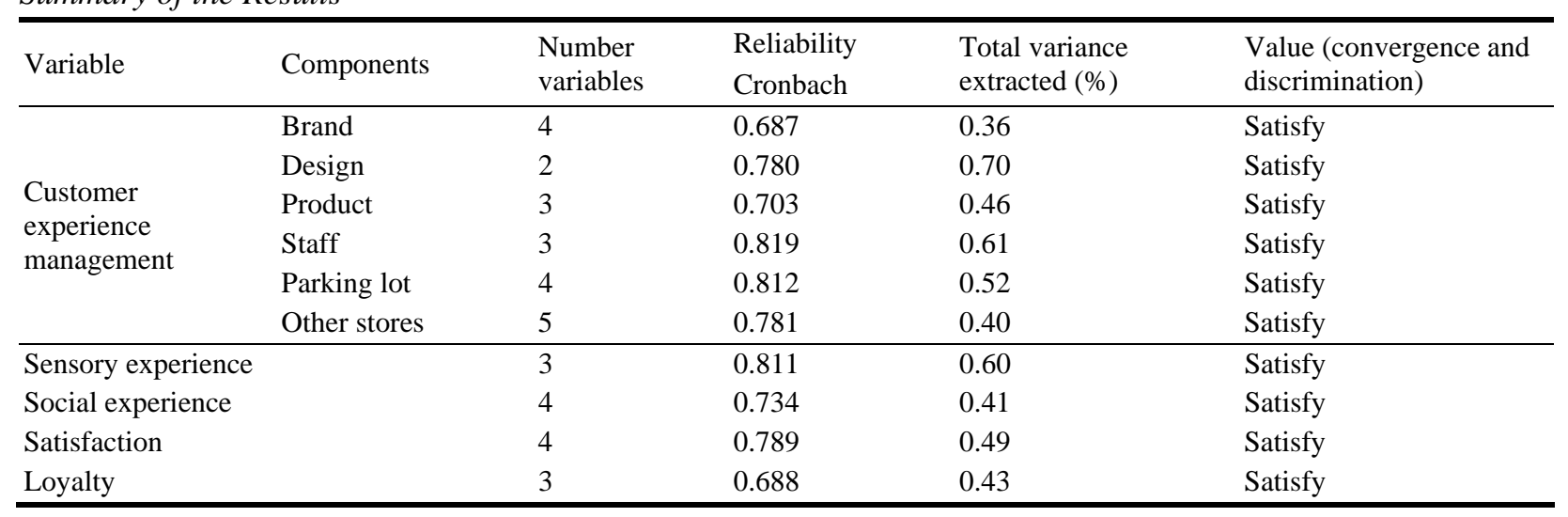

Source: The results from survey 321 respondents. 


\section{Confirmative Factors Analysis (CFA)}

+ CEM variable: after processing data, the results showed that CEM consists of six components with 21 observed variables. CFA showed the model is consistent with market data and satisfied condition of CFA (Chi-squared $=324.359, p=0.000$ value, degree of freedom of 173 , Chi-square $/ \mathrm{df}=1.875<2$, CFI $=0.928$, TLI $=0.912$, RMSEA $=0.052$ ). The weight $\left(\lambda_{\mathrm{i}}\right)$ is satisfied with greater 0.5 and statistically significant $p$-values are equal 0.000. The correlation coefficient between the components is less than 0.9.

+ Sensory experience, social experience, satisfaction, and loyalty variables: similarly the results showed that this model fits the market data and satisfied condition of CFA (Chi-squared $=174.399$, TLI $=0.911, \mathrm{CFI}=$ 0.930 , RMSEA $=0.067)$. The weights of the four scales are satisfactory and statistically significant $(p=0.000)$.

\section{Structural Equation Model}

The result of SEM achieved compatibility with market data: 446 degrees of freedom; Chi-square/df = $1.738<2$, TLI $=0.892$, CFI $=0.903$, and RMSEA $=0.048<0.05$ (see Figure 2 ).

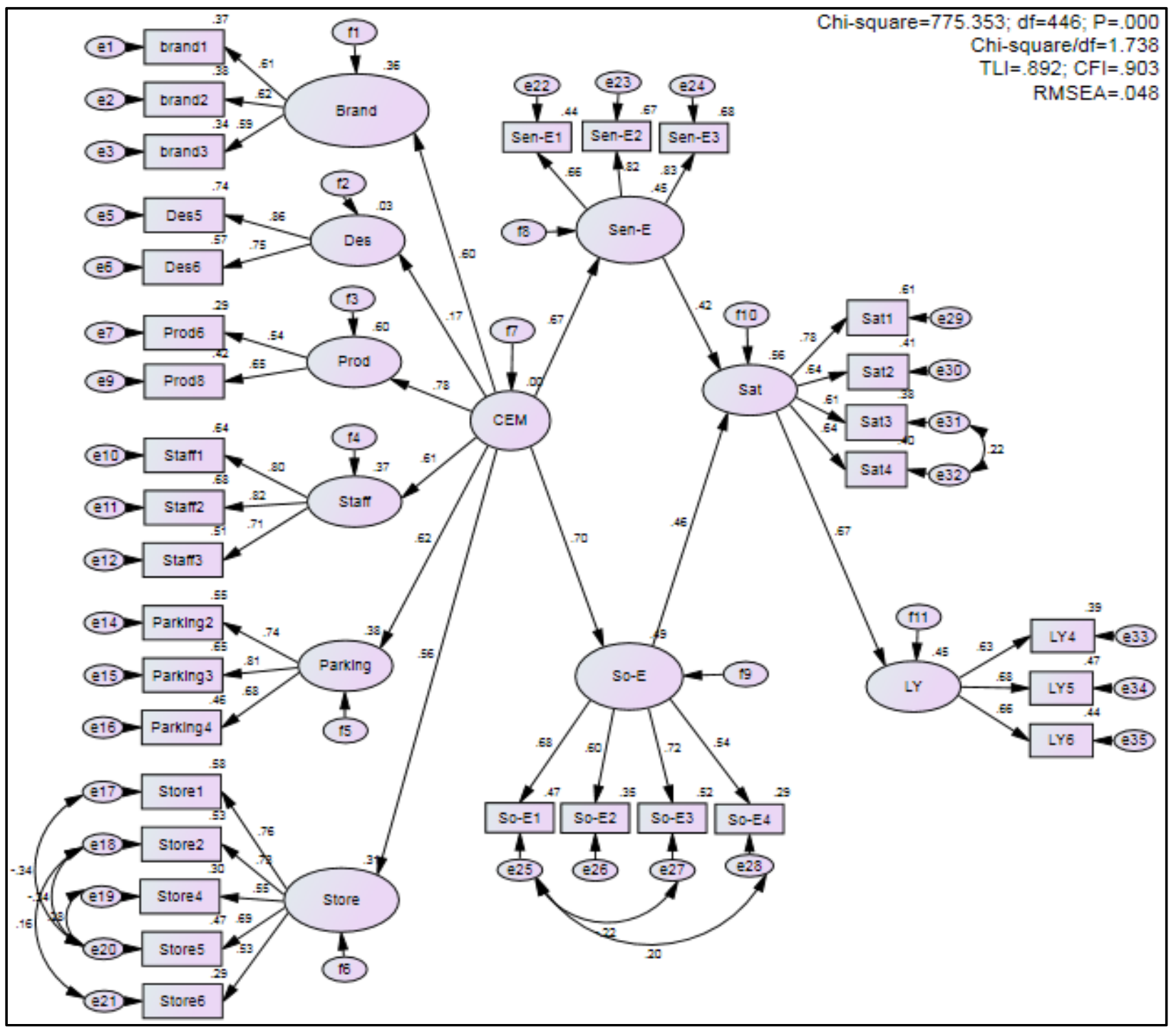

Figure 2. The results of SEM (standardized). Source: The results from survey 321 respondents. 


\section{Analysis and Discussion}

The weights are normalized positive which demonstrated positive relationships (see Table 2). The concept of CEM explained $45 \%$ of the variation of sensory experience with standardized weight gain 0.67 and explained $49 \%$ of the variability of social experience with standardized weights 0.7 . Sensory experience and social experience explained $56 \%$ of the variations of satisfaction with standardized weights 0.42 and 0.46 respectively; Satisfaction concepts explained $45 \%$ of variance of customer loyalty with importance of standardization reaching 0.67 .

SEM results illustrated that all six major components of CEM are positive which demonstrate the impact of these components in the same direction with the customer experience expectations. The factor has the greatest impact on the CEM is commodity (0.78), followed by parking lot respectively (0.62), Staff (0.61), Brands (0.6), The presence of other stores within supermarkets (0.56), and finally the supermarket space and design (0.17). Although SEM results in Figure 2 showed that there is no direct link between the components of CEM and loyalty. However, the indirect relationship between these two concepts exists.

Table 2

Testing Results the Relationship Among Variables and Components

\begin{tabular}{|c|c|c|c|c|c|c|}
\hline \multicolumn{3}{|c|}{ Relationship } & \multirow{2}{*}{$\begin{array}{l}\text { Estimate } \\
0.671\end{array}$} & \multirow{2}{*}{$\begin{array}{l}\text { S.E } \\
0.125\end{array}$} & \multirow{2}{*}{$\begin{array}{l}\text { C.R } \\
5.374\end{array}$} & \multirow{2}{*}{$\begin{array}{l}\mathrm{P} \\
0.000\end{array}$} \\
\hline SenE & $\leftarrow$ & CEM & & & & \\
\hline SoE & $\leftarrow$ & CEM & 0.703 & 0.141 & 4.971 & 0.000 \\
\hline Sat & $\leftarrow$ & SoE & 0.457 & 0.087 & 5.276 & 0.000 \\
\hline Sat & $\leftarrow$ & SenE & 0.417 & 0.075 & 5.591 & 0.000 \\
\hline LY & $\leftarrow$ & Sat & 0.668 & 0.089 & 7.496 & 0.000 \\
\hline Brand & $\leftarrow$ & CEM & 0.604 & & & \\
\hline Des & $\leftarrow$ & CEM & 0.173 & 0.088 & 1.966 & 0.049 \\
\hline Prod & $\leftarrow$ & CEM & 0.777 & 0.147 & 5.304 & 0.000 \\
\hline Staff & $\leftarrow$ & CEM & 0.608 & 0.115 & 5.283 & 0.000 \\
\hline Parking & $\leftarrow$ & CEM & 0.616 & 0.119 & 5.206 & 0.000 \\
\hline Store & $\leftarrow$ & CEM & 0.557 & 0.122 & 4.583 & 0.000 \\
\hline
\end{tabular}

Source: The results from survey 321 respondents.

Table 3

Results of Causal Relationships Between the Factors in Theoretical Models

\begin{tabular}{llllllllllllll}
\hline & \multicolumn{4}{c}{ CEM } & \multicolumn{4}{c}{ SoE } & \multicolumn{3}{c}{ SenE } & \multicolumn{3}{c}{ Sat } \\
\cline { 2 - 13 } & TE & IE & DE & TE & IE & DE & TE & IE & DE & TE & IE & DE \\
\hline SoE & 0.703 & - & 0.703 & - & - & - & - & - & - & - & - & - \\
SenE & 0.671 & - & 0.671 & - & - & - & - & - & - & - & - & - \\
Sat & 0.601 & 0.601 & - & 0.457 & - & 0.457 & 0.417 & - & 0.417 & - & - & - \\
LY & 0.401 & 0.401 & - & 0.305 & 0.305 & - & 0.278 & 0.278 & - & 0.668 & - & 0.668 \\
\hline
\end{tabular}

Notes. TE: total effect; IE: indirect effect; DE: Direct effect. Source: The results from survey 321 respondents.

Table 3 shows the results of a causal relationship of the variables in the model and found that: (1) Direct impact: Customer loyalty is directly influenced by customer satisfaction with standardized coefficients of effects 0.67. (2) Indirect impact: Loyalty is influenced indirectly by the CEM, social experience, and sensory experience with standardized coefficients of effects respectively $0.40,0.31$, and 0.28 . In particular, the impact of CEM on loyalty factor is greater than 1.3 times $(0.40 / 0.31)$ to social experience and greater than 1.4 times to 
the sensory experience. With 5\% significance level, sensory experience and social experience are directly affected by the CEM at the 0.70 and 0.67 . Customer satisfaction is directly influenced by sensory experience and social experience at 0.46 and 0.42 and indirectly affected by the CEM via variables: social experience and sensory experience with the standardized coefficient 0.60 .

Bootstrap testing: This study used a repeated pattern number of 500 samples. The results showed the estimation results are acceptable and trusted.

In short, CEM does not directly affect the customer loyalty that indirectly affects through sensory experience, social experience, and satisfaction. Therefore, the hypothesis $\mathrm{H}_{1}, \mathrm{H}_{2}, \mathrm{H}_{3}, \mathrm{H}_{4}$, and $\mathrm{H}_{5}$ are accepted and hypothesis $\mathrm{H}_{6}$ is rejected.

Structural multi-groups analysis: It was performed to study the model according to the group of qualitative variables such as gender, income, expenditure, age, education, occupation, and supermarkets. Results of Chi-squared test between the two models are presented in Table 4.

Table 4

The Results of Chi-squared Test Between Two Models

\begin{tabular}{llllllll}
\hline \multirow{2}{*}{ Variable } & \multicolumn{3}{c}{ Unconstrained model } & \multicolumn{2}{c}{ Partially constrained model } & \multicolumn{3}{c}{ Difference } & $p$-value \\
\cline { 2 - 8 } & Chi-square & $\mathrm{df}$ & Chi-square & $\mathrm{df}$ & Chi-square & $\mathrm{df}$ & \\
\hline Age & $1,496.275$ & 892 & $1,499.416$ & 897 & 3.141 & 5 & 0.678 \\
Income & $1,473.036$ & 892 & $1,492.270$ & 897 & 19.234 & 5 & 0.002 \\
Gender & $1,470.175$ & 892 & $1,483.862$ & 897 & 13.687 & 5 & 0.018 \\
Spending & $1,379.217$ & 892 & $1,380.798$ & 897 & 1.581 & 5 & 0.904 \\
Marital status & $1,431.442$ & 892 & $1,441.671$ & 897 & 10.229 & 5 & 0.069 \\
Education & $1,463.490$ & 892 & $1,482.708$ & 897 & 19.218 & 5 & 0.002 \\
Occupation & $1,440.292$ & 892 & $1,455.596$ & 897 & 15.304 & 5 & 0.009 \\
Supermarket shopping & $1,546.181$ & 892 & $1,559.939$ & 897 & 13.758 & 5 & 0.017 \\
\hline
\end{tabular}

Source: The results from survey 321 respondents.

The results showed that age, spending for shopping at supermarkets, and marital status of the client do not change the relationships in the research model. Therefore, these factors would not be considered in setting up CEM program. Besides that, the characteristics of income, gender, education, occupation, and shopping at different supermarkets could affect the relationships in the model. So the CEM program needs to pay attention to these differences in order to see whether or not to invest any element to satisfy customers without wasting resources. Differences are discussed in detail as following:

Comparison by income group: The main difference of the two groups of customers with different income was affected in the relationship between the CEM and sensory experience; between sensory experience and satisfaction. For the income group of between two million dong/month or more, the relationship is significant $(p<0.05)$ but not significant in the group of customers with incomes below two million/month $(p>0.05)$. Results also indicated that while supermarket staff, parking lot and the presence of other types of stores inside supermarkets do not impact on the experience of customer whose income is less than two million/month when shopping at the supermarket, the factors that affect the experience of other groups.

Comparison by gender: The results found that the main differences of the two groups of men and women are affected in the relationship between supermarket design and space and CEM. This relationship is significant $(p<0.1)$ for men but not significant in the case of women group. 
Comparison by education level: The results presented that the main difference of these two different groups of educated respondent impact the relationship between supermarket design and space and CEM. For the group with college degrees, this relationship is significantly $(p<0.05)$ but it is not significant for the group without college degrees ( $p=0.834>0.05$ ). When customers are satisfied with shopping at the supermarket, the group of customer without college degrees would have a higher level of loyalty compared with other groups. This has important implications as the clients with college degree are quite hard to serve them and should pay more attention on this group. They pay attention to the commodities, supermarket brand, and parking lot. Additionally, the understanding in some aspects of social experience for this group should be reviewed by the managers.

Comparison by occupation: The results showed that difference occupation impact to the relationship between sensory experience and satisfaction. To the business group, civil servants, workers, and employees groups, this relationship is significant $(p<0.05)$ but not significant in the case of student group and other professions $(p>0.05)$. In the components of the CEM, there is no difference between the two groups. While supermarket commodity is an important factor in creating customer experience for business groups, civil servants, workers, and employees, the impact of this factor to group of students, vocational students and others is not significant $(p>0.05)$. For the group of students, vocational students and others, supermarket staff is an important factor that makes the experience for these groups.

\section{Conclusion}

Nowadays it is not easy to be differentiation, while similar products, prices, and services are becoming ever more regulations. Differentiation will appear in the customer's mind on the basis of brand identity, perceptions, and feelings about the company. All will be managed and delivered through the customer experience. The customer experience will make a difference to the company, building loyalty and will ultimately lead to growth and the rising profits. With such practical significance, CEM is becoming a new wave of management activities in order to build customer loyalty. Theoretically, this study contributes and enriches the research on CEM in the case of supermarket industry in the Mekong Delta. The results of this study showed that CEM in the supermarket sector in the Mekong Delta consisted of six components: (1) supermarket brand; (2) supermarkets space and design; (3) supermarket commodities; (4) supermarket staff; (5) car parking lot; and (6) the presence of different types of stores inside the supermarket. The results also illustrated that customer loyalty is directly positively affected by customer satisfaction. Although the components of the CEM do not directly affect loyalty, they indirectly influence loyalty through direct effects of customer experience and satisfaction. Thus, to maintain customer loyalty, supermarkets need solutions to improve the level of customer experience and satisfaction, and social experience should be considered as well.

\section{References}

Ceribeli, H. B., Merlo, E. M., Senesi, S., \& Palau, H. (2012). A comparative analysis of consumer experience in Brazil and Argentina. Revista Alcance-Electronic, 19(2), 259-272.

Chaudhuri, A. (1999). The effects of brand attitudes and brand loyalty on brand performance. European Advances in Consumer Research, 4.

Fornell, C., Johnson, M. D., Anderson, E. W., Cha, J., \& Everitt Bryant, B. (1996). The American customer satisfaction index: Nature, purpose, and findings. Journal of Marketing, 60, 7-18.

Grewal, D., Levy, M., \& Kumar, V. (2009). Customer experience management: An organizing framework. Journal of Retailing, 85(1), 1-14. 
Kamaladevi, B. (2010). Customer experience management in retailing. Business Intelligence Journal, $3(1), 37$ - 54.

Oliver, R. L. (1997). Satisfaction: A behavioral perspective on the consumer. New York: McGraw-Hill.

Pine, B. J. I., \& Gilmore, J. (1998). Welcome to the experience economy. Harvard Business Review.

Reichheld, F. F., Markey, R. G. J., \& Hopton, C. (2000). The loyalty effect: The relationship between loyalty \& profits. European Business Journal, 12(3), 134.

Rust, R. \& Zahorik, A. (1993). Customer satisfaction, customer retention, and market share. Journal of Retailing, 69(2), $193-215$.

Schmitt, B. H. (2003). Customer experience management: A revolutionary approach to connecting with your customer. New Jersey: Wiley and Sons.

Shen, Y., \& Zhao, P. (2005). A comparative research on consumer complaint behavior. Acta Psychological Sinica, 37(3), 397-402.

Sirdeshmukh, D., Singh, J., \& Sabol, B. (2002). Consumer trust, value, and loyalty in relational exchanges. Journal of Marketing, 66(1), 15-37.

Smith, S., \& Wheeler, J. (2002). Managing the customer experience. London: Prentice Hall.

Verhoef, P. C., Lemon K. N., \& Parasuraman A. (2009). Customer experience creation: Determinants, dynamics. Journal of Retailing, 85, 31-41.

Wijaithammarit, S., \& Taechamaneestit, T. (2012). Customer experience management influences customer loyalty: Case study of supercenters in Thailand. International Proceedings of Economics Development \& Research, 50, 47-52.

Yoo, B., Donthu, N., \& Lee, S. (2000). An examination of selected marketing mix elements and brand equity. Journal of the Academy of Marketing Science, 28(2), 195-211. 